\title{
Multi-unit turns that begin with a resaying of a prior speaker's turn
}

\author{
Klara Skogmyr Marian ${ }^{\mathrm{a}, \mathrm{b}, *}$, Taiane Malabarba ${ }^{\mathrm{c}}$, Ann Weatherall $^{\mathrm{d}}$ \\ ${ }^{a}$ Center for Applied Linguistics, University of Neuchâtel, Rue de la Pierre-à-Mazel 7, CH-2000, Neuchâtel, Switzerland \\ ${ }^{\mathrm{b}}$ Centre for Research on Bilingualism, Department of Swedish Language and Multilingualism, Stockholm University, SE-106 91 \\ Stockholm, Sweden \\ ${ }^{\mathrm{c}}$ Department of English and American Studies, University of Potsdam, Am Neuen Palais 10, Building 19, Room 1.29, 14469, Potsdam, \\ Germany \\ ${ }^{\mathrm{d}}$ School of Psychology, Victoria University of Wellington, P.O. Box 600, Wellington, New Zealand
}

\section{A R T I C L E I N F O}

Article history:

\section{Keywords:}

Multi-unit turns

Repetitions

Collaborative completions

Epistemics

Turn-extension

\begin{abstract}
A B S T R A C T
This study examines the interactional workings of multi-unit turns that have an initial turn-constructional unit that re-says the immediately prior single-unit turn produced by another speaker. Based on cases in English, Portuguese, and French, our analysis shows that resayings do confirming and also 1 ) index the speaker's rights over the propositional component of the words, and 2) support the extension of the turn. In addition to confirming, resayings thus claim rights to what has been said and demonstrate an entitlement to say more. The resayings thereby have both a retrospective and prospective function, the latter being closely related to turn-taking management. Our findings contribute to the existing literature on other-repeats by considering what these do in a multi-unit turn environment.
\end{abstract}

(c) 2021 The Authors. Published by Elsevier Ltd. This is an open access article under the CC BY-NC-ND license (http://creativecommons.org/licenses/by-nc-nd/4.0/).

\section{Introduction}

This study investigates a specific form of multi-unit turn. It describes the sequential environment in which this phenomenon occurs and shows what is being done in the turn. Our target phenomenon is a multi-unit turn in which the first unit of the turn re-says, by repeating exactly or almost exactly, the words of the prior single-unit turn produced by another speaker. As Schegloff (2004) noted, there is an important distinction to be made with repeats. Repeating is saying the same thing for a second time. However, repeats can also be 'for another first time' (Garfinkel, 1967:9, cited by Schegloff, 2004), as regularly occurs in overlap resolution and in same-turn repair segments. In this study we are interested in the first of these, that is, resayings that are designed to be recognisable as 'repeating' what the previous speaker has just said.

A further key analytic distinction for repeats is between repeating that is doing an exact repeating (e.g. Schegloff, 1996; 2004) and repeating that is designedly modified to do something else, such as claiming primary rights from second position (Stivers, 2005). The phenomenon we examine is doing a repetition, even if the forms of the first saying and second saying, the 'doing a repetition', sometimes slightly differ. From our analysis of multi-unit turns that begin with a resaying of the previous speaker's whole turn, we find that subsequent units further advance an ongoing action that had previously been underway by

\footnotetext{
* Corresponding author.

E-mail addresses: klara.skogmyr@unine.ch (K. Skogmyr Marian), tmalabar@uni-potsdam.de (T. Malabarba), Ann.Weatherall@vuw.ac.nz (A. Weatherall).
} 
the same speaker, which in our data included complaining, explaining and telling news. Thus we propose that, in addition to confirming, which has previously been observed as a key function of other-repeats (see below), turn-initial full repeats claim primary rights to the words that have been said, and they prospectively facilitate the production of an additional unit of talk.

While there is already a substantive body of conversation analytic work on other-repeats (see Section 3), these studies have not concentrated specifically on the ramifications of repeats from a turn-taking perspective, which is the focus of the present paper. Our study thus contributes to a better understanding of both the interactional workings of repeats and of turntaking organisation. Starting with a review of literature on multi-unit turns (Section 2) and of other-repeats (Section 3), we then describe our data (Section 4). In our analysis, we present two interactional environments in which repeats in multi-unit turns occur (Section 5), before discussing our results in terms of what they contribute to understanding the accomplishment of multi-unit turns (Section 6).

\section{Multi-unit turns}

A multi-unit turn can be considered an interactional accomplishment where something other than basic practices governing turn construction is at play. When simple turn taking is in operation, there is a structural organisation that functions to minimise turn size (see Schegloff, 1996). The structural feature of the turn-taking system that keeps turns of talk short is a consequence of the units out of which turns of talk are built. A key characteristic of turn-constructional units is that they are projectable as a possibly complete turn of talk where speaker change can occur. It is the transition-relevance place that occurs somewhere before the actual completion of each turn-constructional unit that works to keep turns of talk just one-unit long. The practices for speaker allocation at each transition-relevance place are spelt out in the conversation analytic model of turn taking (Sacks et al., 1974). A basic gloss of turn-allocation practices is that if a next speaker is not selected, then someone else can self-select or a current speaker can continue speaking.

Although the turn-taking system operates to keep turns short, multi-unit turns do occur. Turns of various sizes are one of the grossly apparent facts documented in the Sacks et al. (1974) conversation analytic model of turn taking. Storytelling is one environment for multi-unit turns and pre-announcements are a resource through which rights to a telling are accomplished (Schegloff, 2007). Apologies at the opening of an interaction can also function as a pre-beginning, projecting a next action such as asking for directions (Mondada, 2019).

Responses in adjacency pair sequences are another typical place where multi-unit turns occur because speakership rights are upheld until conditional relevance has been fulfilled (Schegloff, 2007). Other practices for accomplishing a multi-unit turn include using prospective indexicals (Goodwin, 1996) or conjunctionals (conjuctions, conjunct adverbials, and discourse markers; see Couper-Kuhlen and Selting, 2017), pivot constructions (Betz, 2008; Clayman and Raymond, 2015) and compressing the transition-relevance place by phonetic means, for example, with rush-throughs (Walker, 2010), list intonation (Selting, 2007), and abrupt joins (Local and Walker, 2004).

In turn-initial position, resources regularly deployed to signal an extended turn include misplacement markers such as by the way (Sacks and Schegloff, 1973) and well-prefacing (Schegloff and Lerner, 2009). Although repeats can preface a turn (Bolden, 2009), they have not yet been associated with turn extension. To the best of our knowledge, repeating has rarely been discussed with respect to the organisation of turn taking. One exception is the observation that in a multi-unit turn a speaker can repeat something that was said at the beginning of the turn to indicate that simple turn taking is back in operation (Schegloff, 2009).

\section{Repeating or resaying a prior speaker's talk}

Repeats are pervasive in talk and have been found to perform a variety of actions depending on who does the repeat, how it is done and where it occurs. This literature review focuses on studies on other-repeats, that is, repeats consisting of resayings of a prior speaker's talk, in various languages including the ones investigated in this study (English, French, Brazilian Portuguese).

One well-documented place in which other-repeats occur is in response to polar questions. For many languages, including English, there is a 'yes/no' system which provides for doing the simple action of agreeing with the positively or negatively formatted proposal in the polar question. As Raymond (2003) and Heritage and Raymond (2012) have noted, things other than a yes or no in response to polar questions are non-conforming. That is, repeating in response to polar questions is marked and does more than just affirming the propositional content of the question. According to Heritage and Raymond (2012), repeating in this position is more agentive than type-confirming responses, and a way for the speaker to claim epistemic primancy over what is said. The same authors also parenthetically suggest that repetitions are "associated with sequence expansion" (Heritage and Raymond, 2012:186), but they do not further elaborate on this issue.

In a multi-language study of responses to polar questions, Enfield et al. (2019) also found that responses that repeat part of or the entire question are marked in that they do more than just affirming the question. Confirming earlier findings, they noted that other-repeats can be deployed to challenge the epistemic asymmetry that exists between parties in questionanswer sequences. They also proposed that repetitional answers have bearing on two additional aspects of asymmetrical interpersonal dynamics operating in question-answer sequences. By initiating an adjacency pair action, the questioner claims both sequential and thematic agency, obliging the recipient to respond, on a particular topic. According to Enfield et al. (2019), 
repetitional answers may be deployed by the answerer to claim back thematic agency over the propositional content of the question.

The findings about other-repeats in French generally align with the results of the abovementioned literature, showing for example how other-repeats may be used to show agreement or alignment with a first turn (Traverso, 2012; Ursi et al., 2018), to mark the involvement in a shared activity (Stoenica, 2014), and to negotiate issues of speakership and epistemic authority (Traverso, 2012). Ursi et al. (2018) recently investigated the main uses of other-repeats in the large French-language corpus CLAPI (CLAPI). Among these were (1) repetition of an assessment to show agreement, (2) other-repair (to initiate or complete repair), and (3) repetition to mark receipt. Persson (2015a; 2015b) has more specifically documented how speakers use second position registering repeats to offer an opportunity for the recipient to respond without soliciting a response (Persson, 2015a), and ah-prefaced repeats to acknowledge another speaker's turn while indexing a previous turn by the same speaker as somehow inadequate (Persson, 2015b).

A much smaller body of research has investigated other-repeats in Brazilian Portuguese interaction. Studying interactions in telephone helpline services, De Souza (2009) and Ostermann and De Souza (2011) showed how other-repeats were systematically followed by a confirmation from the caller and therefore used by call takers as understanding checks that allowed them to proceed with the service being requested. In the context of interviews between abused women and the police, Guimarães (2007) claimed that repetitional answers in Brazilian Portuguese are "'default' in ordinary conversation" (p. 41) and that interjections (the equivalent of yes/yeah) are instead marked answers. In their cross-linguistic study on polar answers, Enfield et al. (2019) found that repetitional answers in Brazilian Portuguese were more often provided when they followed a request for new information than when they responded to requests for confirmation or understanding checks. Most importantly, unlike what Guimarães (2007, see also Urbano et al., 2002) have claimed, Enfield et al. showed that repetitional answers are not the norm in Brazilian Portuguese. As with the other languages they investigated, repetitional answers in Brazilian Portuguese do not simply confirm what has just been said, but confirm the very "proposition that has just been put on the table by the questioner" while also claiming "a degree of thematic agency, or independent interest over that proposition" (Enfield et al., 2019:16).

Also relevant for our study is research on repeats in the context of collaborative completions. The phenomenon of collaborative completions was first documented by Sacks et al. (1974) and further examined by Lerner (2004). Collaborative completions occur when one participant completes another speaker's turn in-progress. Such completions may be done either in an anticipatory manner, without invitation from the first speaker, or to respond to self-initiated repair such as word searches. An interpersonal dynamic that is clearly in operation in the context of collaborative completions is that these reduce the original speaker's entitlement to the current talk. Such entitlement can be regained in the receipt slot, however, which is often oriented to "as a place for the original speaker to address the adequacy of the proffered completion" (Lerner, 2004:233). In this position, repeats are generally understood to do similar work as confirmation tokens, namely acknowledging, confirming and agreeing with the candidate completion. However, in her investigation of collaborative completions in everyday French conversations, Oloff (2014) found that simple affirmations of the type yes (French oui or ouais) after a candidate completion indicates that the speaker treats the completion as a possible completion but not exactly the one projected by the speaker. Repeats, on the other hand, more clearly validate the adequacy of the candidate completion, while also allowing the speaker to maintain the progressivity of the talk by simply integrating it in the continued turn. Similarly, when repeats are produced after completions that respond to a word search (Goodwin and Goodwin, 1986; Lerner, 1996), they do not just confirm that the delivered content matches what was being searched for, but they claim the original speaker's higher epistemic authority over the ongoing talk regardless of the speaker's "failure to complete the search on his/her own" (Kristiansen et al., 2017:391).

In sum, prior research on other-repeats shows that these can be used by speakers as a practice to claim some sort of locally relevant rights over what is said and whose words they are. Enfield et al.'s (2019) study is highly convincing in this context, as it shows convergence across a number of different languages. Enfield et al. (2019) did not distinguish between exact and modified repeats nor whether it was the full or only parts of the turn that was repeated, however it seems reasonable, though, to expect that our target phenomenon - resayings that are doing exact repeats - strongly asserts the epistemic and thematic agency of the speaker doing the repeating. This proposal is supported by the fact that environments in which exact resayings recurrently occur in our data include tellings and collaborative completions, where the person doing the repeat uses the repeat to resume or refine a telling or turn-in-progress.

In terms of turn taking, the literature is less clear on the function of other-repeats. Some studies have touched upon this issue in the passing (Heritage and Raymond, 2012; Oloff, 2014), suggesting that there may be a link between other-repeat and turn extension. In the context of collaborative completions, Oloff (2014) also observated that simple repeats were more frequent when the turn-completions occurred in the beginning of a projected longer turn by the first speaker, such as in the context of explanations or tellings, than toward the end of such turns, supporting our suggestion that repeats may be used to continue a prior action.

Our analysis contributes to the body of work on other-repeats by focusing specifically on repeats in multi-unit turns. We show two environments in which resayings working to claim back the right to a longer turn of talk occur: after an expression of a candidate understanding and after a collaborative turn-completion. 


\section{Data}

Our collection of 30 cases was assembled by searching through several substantive number of sizeable corpora including audio-recorded telephone conversations and video-recorded face-to-face interactions in English (American, British, New Zealand), Brazilian Portuguese, and French. While some of the data come from institutional environments, we have only included cases from conversational interactions in which regular principles of turn-taking are in place (see Sacks et al., 1974, and discussion above). All conversations involved 2-4 participants. A more detailed description of the material that was searched is given below. The rather small number of cases drawn from such amount of data suggests that our target phenomenon is relatively rare.

The English-language data come from different sources. One is a corpus assembled for the 2017 Summer Institute for Advanced Conversation Analysis which was drawn from corpora held by the instructors. These included the Newport Beach, Santa Barbara Ladies and the Holt corpus, but also more recently recorded interactions. Our target phenomenon was originally observed in the summer institute data, including Excerpts 2 and 3, below. New Zealand English data come from telephone calls in the Wellington Corpus of Spoken New Zealand English, nearly 200 calls from a dispute resolution service, over 400 calls to a victim support helpline and a range of miscellaneous recordings collected as teaching/learning exercises.

The Brazilian Portuguese cases come from an interview generated for a project on language teaching (Malabarba, 2010) in which the researcher interviewed the director of a language school. The interview was carried out in an open-ended, conversational style. It is 75 min long and was video-recorded in 2008.

The French-language collection is based on video recordings of informal discussions among friends. These recordings include coffee break conversations between university students in a university cafeteria in the French-speaking part of Switzerland (corpus Pauscaf), and recordings of aperitifs/dinners among friends in France (recordings 'Chat' and 'Kiwi' in the corpus CLAPI). ${ }^{1}$ All participants are young adults, and the interactions are non-institutional, ordinary conversations among people who know each other from before. The conversations vary in length from 5 to $55 \mathrm{~min}$, and the total length of the recordings is approximately $10 \mathrm{~h}$.

The repeats included in the collection are resayings of a prior speaker's entire single-unit turn. Following Schegloff (1996, 2004), we only analyse cases of other-repeats that do an exact resaying of the prior turn, i.e., which repeat the words of the first turn, sometimes with the addition or omission of some 'dispensable' items such as turn-initial or turn-final discourse markers (see Schegloff, 2004). At times, the repeat is delivered with different prosody than the original turn, but it is nevertheless produced as 'doing a repetition'.

\section{Analysis}

The structural composition of our phenomenon may be summarised as follows:

Turn 1: A single turn-constructional unit turn that displays an inference about prior talk by another speaker

Turn 2: A resaying of Turn $1+$ turn extension into a multi-unit turn

We present two recurrent types of environments where our phenomenon occurs, namely (1) repeats that resay an upshot, formulation or other action that is based on an inference about the preceding talk; and (2) repeats that resay collaborative turn-completions (which are also based on an inference). The analysis presents evidence to support our claim that resayings as a first unit in a multi-unit turn claim rights to what has just been said and then facilitate an entitlement to say more. The 'more' either fine-tunes the content of the repeat, or resumes and furthers the speaker's prior action (telling, explaining, etc.). The excerpts chosen are the clearest from our collection that also show our phenomenon being used in the different languages we examined.

\subsection{Resayings of candidate understandings of prior talk}

Excerpts 1-3 show cases where a candidate understanding of the preceding talk is repeated. These are all examples that are similar to Schegloff's (1996) cases of confirming an allusion, in which the repeat confirms something that has been only alluded to before. The analysis focuses on what the turn extension does. In all cases the turn extension includes fine-tuning of what was confirmed, that is, it offers additional information that in some way adds nuance to the confirmation. This finding supports the claim that the repeating is claiming back authority over what is being said.

Excerpt 1 is a telephone call to an organisation that manages complaints about gas and electricity problems, similar to an ombudsman. The caller CAL) is complaining about not having enough hot water. Earlier in the call she told the call taker (CON) that she was 'starkers' - meaning completely naked - because she had been running a bath, but after only a couple of inches the water ran cold and she could not have her bath.

\footnotetext{
${ }^{1}$ The corpus Pauscaf was developed by the Center for Applied Linguistics at the University of Neuchâtel, Switzerland. The corpus CLAPI (Corpus de Langue Parlée en Interaction, ICAR, CNRS UMR 5191 \& Université Lyon 2) is publicly available at clapi.ish-lyon.cnrs.fr.
} 


\section{Ex.1 We should have plenty of hot water}

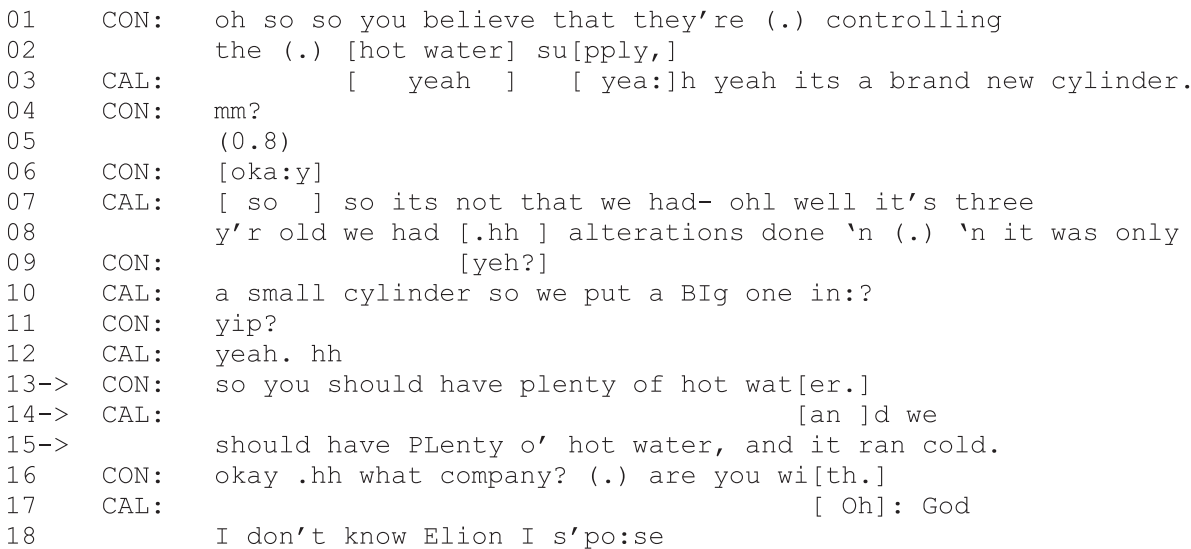

In line 13, the call taker produces a candidate understanding, which in this case is expressed as an upshot, 'so you should have plenty of hot water'. It is a formulation that captures the nub of the complaint. The caller repeats the formulation, 'and we should have PLenty o' hot water' (lines 14-15) to confirm the call taker's candidate understanding and that it was one that was alluded to in the prior talk (Schegloff, 1996). Note that the inference marker 'so' (Blakemore, 1988; Bolden, 2009) in the call taker's candidate upshot (line 13) is replaced in the repeat with 'and' (line 14), which shows that the caller is claiming the words as part of her own turn (Heritage and Sorjonen, 1994). In addition, the emphasis placed on the word 'PLenty' allows the caller to highlight the contrast between what they 'should' have with what they do have, cold water. The extended turn finetunes the complaint component of the talk as the water running cold is attributed to the supplier "controlling the hot water supply' (lines 1-2). So, the caller confirms the call taker's candidate upshot with an identical resaying and extends the turn to fine-tune the details of the complaint.

In the second excerpt, Tony is ringing up Marsha to find the whereabouts of his son Joey, who has been visiting his mother. Joey had driven his father's car to see his mother, but is flying back to his father because the top of the convertible was stolen and it was too cold for him to drive the car without it. It is a case that Schegloff (1996) presents as a case of confirming an allusion. However, our analysis extends that presented by Schegloff by considering the whole of Marsha's turn in line 12 and what it is doing.

\section{Ex.2 Stolen (abridged excerpt appears in Schegloff, 1996:185)}

01 Marsha: Did Joey get home yet?

02 Tony: Well I wz wondering when 'e left.

$03 \quad(0.2)$

04 Marsha: hhh Uh: (d) did Oh: .h Yer not in on what ha:ppen'. (hh) (d)

05 Tony: No $(\mathrm{h}) \mathrm{o}=$

06 Marsha: $=$ He's flying.

$07 \quad(0.2)$

08 Marsha: En Ilene is going to meet im:.Becuz the to:p wz ripped

09 off'viz car which is tih say someb'ddy helped th'mselfs.

10-> Tony: Stolen.

$11 \quad \frac{\text { sto }}{(0.4)}$

12-> Marsha: Stolen.=Right out in front of my house.

13 Tony: Oh: f'r crying out loud, =en eez not g'nna eez not

$14 \quad$ g'nna bring it ba:c $\bar{k}$ ?

In lines 8-9, Marsha describes the top of the convertible being 'ripped off'v iz car which is tih say someb'ddy helped th'mselfs'. Tony then offers a candidate understanding of what Marsha has just said, that the top of the car was 'Stolen' (line 10). In the next turn, Marsha repeats Tony's turn, 'Stolen' (line 12), confirming the candidate understanding and also confirming that it was only alluded to in prior talk (Schegloff, 1996).

In the next unit in the turn, Marsha fine-tunes the confirmed allusion by further specifying where the crime happened: '=Right out in front of my house' (line 12). The marked emphasis on 'right' and 'my' suggests that it is the precise characteristics of the location that is noteworthy: home is a location that should be safe and secure. The extension also functions to mitigate any blame placed on Joey as he had been responsible and looked after the car, parking outside his mother's house where it should have been safe and secure. Tony's response in line 13, starting with 'Oh: f'r crying out loud', shows his shared 
stance of the additional outrage of where the theft happened. The 'oh' is also evidence that Tony is treating Marsha's additional informing as news (Heritage, 1984). Note that the transition-relevant place between the first unit and the second unit in Marsha's turn is compressed, further supporting the observation that she is self-selecting to continue speaking (Walker, 2010).

In the third excerpt, Giselle (GIS) is telling Ned (NED) news about their common friend Christina, and she is trying to establish how informed Ned is about what has been going on with Christina. On delivery of the news that Christina got 'her Google job' (line 1), Ned formulates his candidate understanding that Christina and her partner will be leaving.

Ex.3 They're leaving (from CA=Store Interaction 34, courtesy of Jeffrey Robinson)

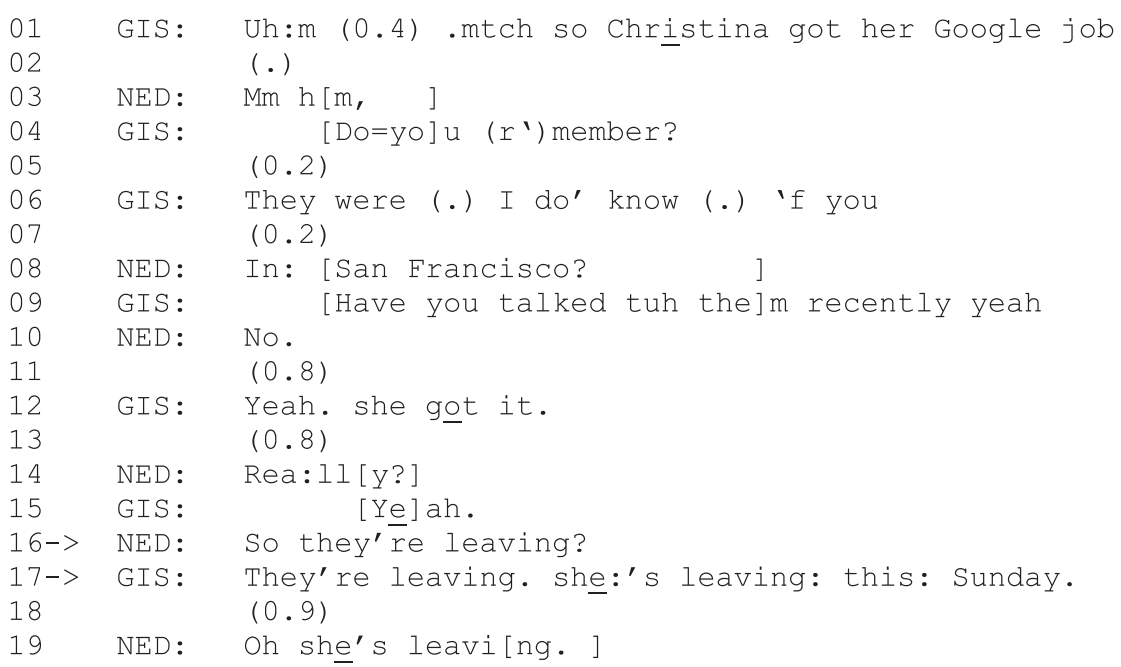

In line 16, Ned offers a candidate understanding ('So they're leaving?') of the significance of the news being told by Giselle: Christina and her partner are leaving because Christina got the job. Ned's candidate understanding is 'so'-prefaced, designed to mark inference (Blakemore, 1988). The turn is formatted as a declarative but the rising intonation turns it into a polar question. In response, Giselle repeats Ned's turn, 'They're leaving' (line 17), dropping the inference marker 'so' to confirm that his candidate understanding is accurate. By producing the repeat Giselle does more than confirming - as this could have been done with a simple confirmation token - she is also confirming that the upshot was only alluded to in the prior talk (Schegloff, 1996). However, although confirmed, Neds formulation of the upshot of the news turns out to be not quite right, as Giselle expands with 'she:'s leaving: this: Sunday' (line 17). The turn extension serves to clarify the significance of the news, that it is not both parties that are leaving right now, just Christina. While Ned's upshot was not incorrect - since in fact, both parties will eventually move - the turn extension works as a hic et nunc fine-tuning of Ned's understanding. This fine-tuning supports the claim that Giselle is not just confirming an allusion but also demonstrating primary entitlement to the news. Ned's change-ofstate token 'Oh' in 'Oh she's leaving' (line 19) aligns with Giselle as news teller by treating it as something new (Heritage, 1984).

To sum up, in this section we have shown three examples of cases in which the repeated turn formulates a candidate understanding of prior talk, and where the resaying is followed by a turn-extension that allows the speaker to elaborate or fine-tune what has been confirmed through the resaying. ${ }^{2}$ In Excerpt 1, the extension fine-tunes the formulation of a complaint. In Excerpt 2, the speaker extends the turn beyond the repeat of the candidate understanding to provide additional information about the news that is being told. In Excerpt 3, the repeated candidate understanding of news is not quite right and the extension fine-tunes the understanding.

\subsection{Resayings of collaborative completions}

In the above cases an inference was made on the basis of prior talk, which the resaying confirmed, providing an occasion to extend the turn. A different kind of inference is made in Excerpts 4-6, where the repeated turn-constructional unit consists of a candidate completion of a turn-in-progress. Here, the speaker who repeats the candidate completion uses it to confirm its accuracy while also gaining back the turn so as to continue the ongoing action. The repeat thus works as a means for the speaker to maintain progressivity of the talk (Oloff, 2014) while also claiming authorship of the words.

\footnotetext{
${ }^{2}$ Although the first three examples are in English we also have French and Portuguese cases, albeit from more extended and complicated sequences that space prohibits presenting.
} 
In Excerpt 4, the director (DIR) of a language school franchise in Brazil is being interviewed by a researcher (RES) in applied linguistics about the teacher training course developed and taught by the director. In answering the researcher's question about the content of the teacher training, the director gives an example of one of the issues teachers are expected to deal with as language teachers, that is, students' expectations regarding their learning.

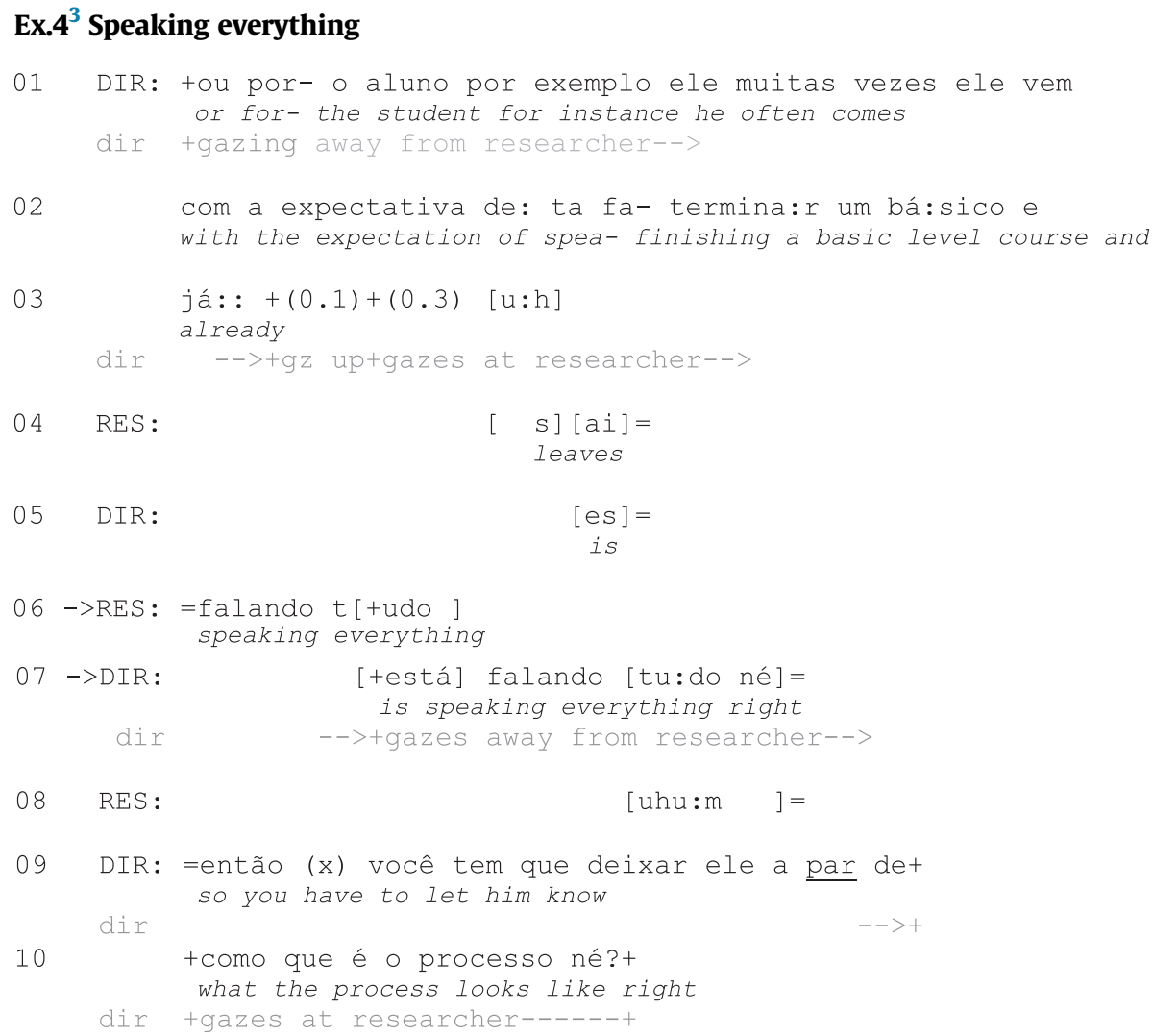

In lines 1-3, the director comments on students' unrealistic expectations in basic level courses. The last word of his turn já ('already', line 3 ) is produced with vowel elongation and a subsequent change in eye gaze direction, from looking away from the researcher (mostly at the camera) to looking up and then directing his gaze at the researcher (line 3). This verbal and embodied conduct is oriented to by the researcher as a word search and an invitation to join the search (see Goodwin and Goodwin, 1986). A candidate turn-completion is then offered by the researcher in lines 4 and 6, in overlap with the director's hesitation marker 'u:h' (line 3) and es ('is', line 5). Note that the director's turn continuation of his own turn is launched immediately as the researcher starts producing her candidate completion, but is withheld until (at least) part of the completion is over (line 6). In line 7, the candidate turn-completion is repeated by the director although in a slightly modified version with the verb to be instead of leave.

By repeating the researcher's candidate turn-completion, the director acknowledges, assesses and ratifies the researcher's turn-completion and its import. In doing so, the director displays his authority over the turn being repeated and the matters it deals with. Assuming então (line 9) functions in a similar way as so-prefacing in English (Blakemore, 1988; Bolden, 2009), this allows the director to regain the floor and continue his prior action, which is informing the researcher about how unrealistic expectations of students can be addressed. By formulating the informing as a general rule, the director claims epistemic primacy of the matter at hand.

In Excerpt 5, four university students in Switzerland are discussing statistics problems for a course. Nathaniel (NAT) is trying to explain to François (FRA) the analysis of variance and its implication for one of the exercises.

\section{Ex.5 It will grow (Pauscaf-15)}

\footnotetext{
${ }^{3}$ Examples 4 and 5 follow the multimodal transcription conventions outlined in Mondada (2019) available at https://www.lorenzamondada.net/ multimodal-transcription. Idiomatic translations to English appear below the original transcript lines in italics; since there are no major differences in word order between the languages, translated words have been placed under the original words whenever possible to facilitate reading.
} 


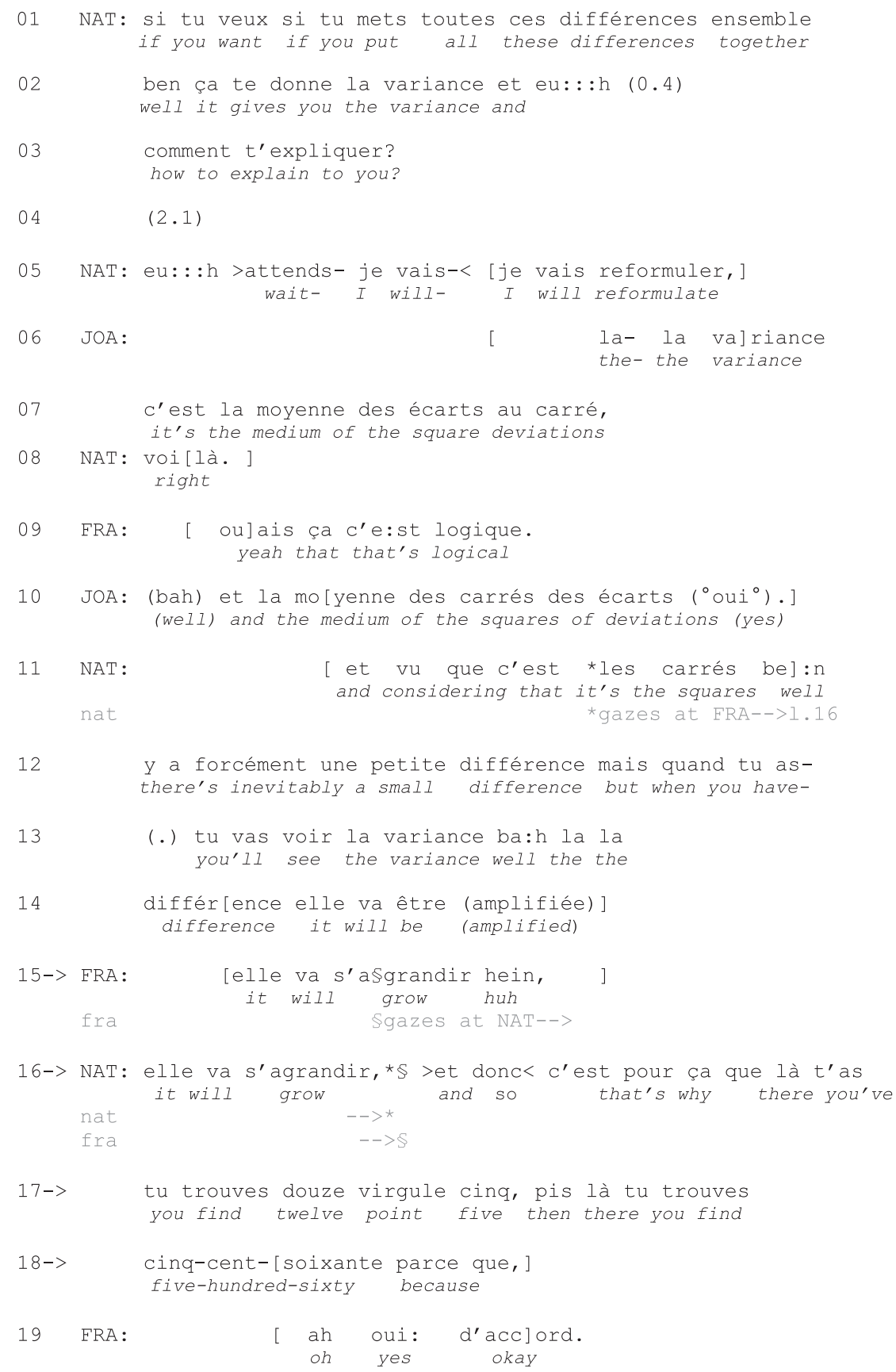

In lines 1-2, Nathaniel begins his explanation but encounters some difficulties (see speech perturbations in line 2, and the meta-question in line 3). As he announces that he will reformulate his explanation (line 5), Joanne (JOA) offers an explanation of the variance itself (lines 6-7). The accuracy of this explanation is confirmed by Nathaniel (line 8) and qualified by François as being logical (line 9). As Joanne slightly reformulates the explanation of the variance (line 10), Nathaniel expands by returning to the implication of the observed difference for the specific statistics problem (lines 11-14). As he approaches the final consequence for 'the difference', he slightly hesitates again (see elongated vowel sound on bah and repeated article in line 13). At this point, François offers a candidate turn-completion elle va s'agrandir hein ('it will grow huh', line 15) that grammatically fits Nathaniel's turn and displays François's understanding of the explanation so far: that the difference will grow. By adding the turn-final hein (approx. 'huh') and gazing at Nathaniel, François slightly downgrades the epistemic certainty (Heritage, 2012) of his completion and orients to the relevance of a confirmation. 
Although Nathaniel himself already completed his turn in overlap with François's candidate completion, he repeats François's elle va s'agrandir ('it will grow') in line 16 to confirm his acceptance of the candidate completion and he then extends the turn into a multi-unit turn in which he asserts that the explanation so far is the reason for the numbers in the exercise (lines 16-18). In repeating François's turn-completion rather than his own, Nathaniel shows his emic orientation to the fact that the repeat, delivered as a repeat, serves specific purposes in the interaction. The repeat thus confirms the accuracy of François's inference; accepts his candidate turn-completion. The et donc ('and so') additionally works as a means for Nathaniel to resume the prior action of explaining the statistics problem. François, in turn, finally displays his understanding and acceptance of the complete explanation (line 19).

In the final example (Excerpt 6), Giselle is suggesting that a group of mutual friends organise a short vacation together.

\section{Ex.6 In Bend (from CA=Store Interaction 34, courtesy of Jeffrey Robinson)}

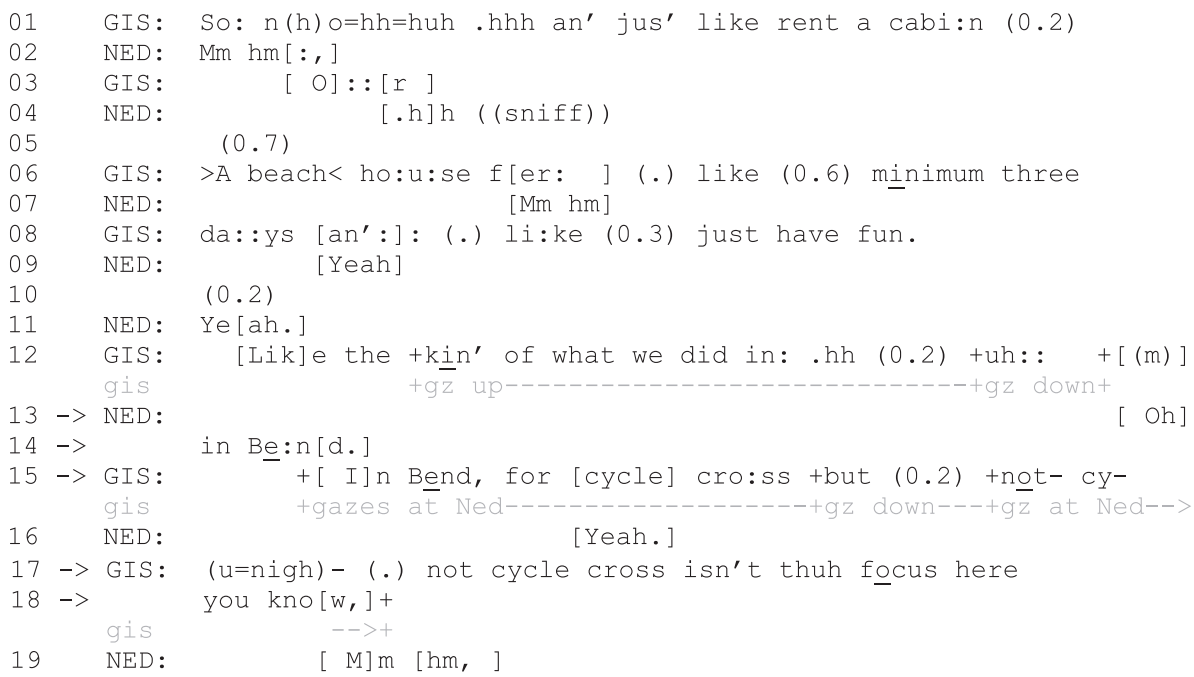

After suggesting the kind of house that the friends would rent (lines 1 and 6), the length of the stay (line 6), and what they would do ('just have fun', line 8), Giselle starts comparing this future trip they are talking about with what they did on a previous trip (line 12). However, as she encounters difficulties with producing the name of the place where they went (see speech perturbations and gaze aversion suggesting a word search, line 12), Ned completes her turn with 'Oh in Be:nd.' (lines 13-14). The delivery of this turn, with emphasis on 'e' and falling intonation, suggests a high degree of certainty. Giselle, in partial overlap with the end of Ned's turn, immediately accepts his completion by repeating it (line 15). She then continues and elaborates on the comparison between the planned and the past trip. Even though the candidate completion was confirmed, it turns out that there were some considerable differences between the trip to Bend and the trip Giselle is currently suggesting, and she uses the turn-extension to clarify that the focus of the past trip (cycle cross) would not be the focus of the new trip (lines 15 and 17-18).

Giselle's resaying of Ned's candidate turn-completion confirms that this is what she was going to say. What follows in the turn, when she elaborates on the focus of the new trip, that is, having fun instead of cycle crossing, thus works to reclaim her status of main proponent of the future trip. So, here claiming back the words as part of her turn is a way of also claiming back her right to continue with what is relevant to her.

In sum, this section has shown three examples of resayings of candidate turn-completions, which are subsequently developed into a multi-unit turn. The resayings confirm the accuracy of the candidate understandings expressed in the first turn, thereby claiming entitlement to the words, and also work prospectively to get another unit of talk, thus extending the turn. These last three cases highlight the turn-taking-regulatory function of repetitions, as these allow speakers to smoothly resume their turn and continue with their ongoing action.

\section{Discussion and conclusion}

While there is a substantial literature on other-repeats, relatively little attention has been payed to what comes after the repetitions. In this paper, we have addressed other-repeats from a turn-taking perspective, by investigating the role of turninitial other-repeats in multi-unit turns. Our main argument is that our target phenomenon, the confirming, 'doing a repetition', displays and claims an entitlement to the words that have been said and tilts the right to say more to the current speaker, thereby facilitating an extension into a multi-unit turn. The analysis documented two different types of sequential environments in which such turn-initial resayings occur in multi-unit turns. In both cases, the first turn involves expressing an inference of the prior talk, which provides an environment where confirming is relevant. 
The first part of the analysis involved cases in which the repeats were resayings of an upshot, formulation, or other action that expressed, in words, an inference about what had just been said by the other speaker. While the repeat at first confirms the expressed candidate understanding, it turns out that the thing that has been confirmed is not quite right or sufficient from the perspective of the speaker. In Excerpt 1, the complaint is not that there is not enough hot water, it is rather that the water ran cold. In Excerpt 2, the news was not just that the roof of the car was stolen but that it happened right outside Marsha's house. In Excerpt 3, the news conveyed by Giselle is not, as formulated by Ned, that they're leaving (right now). It is rather that she, Christina, is leaving. In these cases, the extension of the turn into a multi-unit turn allows the speaker to fine-tune the understanding that has been expressed through the confirming repeat. This finding points to the fact that the repeat is used to do more confirming; namely to claim the right to continue. In a way, the fine-tuning contrasts with the findings of Oloff (2014), who noted that repeats (although of collaborative completions) were stronger displays of acceptance and confirmation than standalone confirmation tokens. In our study the repeats claim back the words and point the way to say more. It seems likely that the strong assertion of agency a speaker claims in repeating the words just uttered by another is an accountable matter because normatively confirmation would be done by a simple yes or no (Enfield et al., 2019). Adding another unit of talk provides a structural solution where an explanation for doing more than confirming can be found.

The second part of the analysis included cases of collaborative completions, in which speakers deployed repeats to accept candidate turn-completions and continue speaking. In all cases offered as illustrations, the candidate completions occurred after some self-repair by the first speaker. While in Excerpts 4 and 6 the candidate completions are offered following considerable speech perturbations (Excerpt 6) and an embodied invitation to join a word search (Excerpt 4), the completion in Excerpt 5 was offered in more of an anticipatory manner, albeit also after some minimal self-repair. The contiguous nature and grammatical fittedness of the candidate completions point to the affiliative nature of such completions (Lerner, 2004): By completing the turn, the coparticipant helps the speaker continue. Similarly, the speaker's resaying of the completion may be considered an affiliative move in that it both accepts and integrates the repeated words in the own turn. At the same time, the repeat allows the speaker to regain authority and claim primary entitlement to the same words - which can be understood as a display of agency. It therefore seems that the repeat works as a way to display alignment and affiliation while simultaneously claiming entitlement both retrospectively of the turn so-far and prospectively of its continuation.

Noteworthy is that in our examples, the speaker has already had provision for a multi-unit turn, for example by presenting a reason for a call (Excerpt 1), telling news (Excerpts 2 and 3), or explaining a complex statistical problem (Extract 5). This fact does not undermine our analysis; on the contrary, we consider this as a support for our case. As noted by Schegloff (1982), multi-unit turns may be considered collaborative interactional achievements, and the accomplishment of larger courses of action requires collaborative efforts from the participants involved. News recipients may do so by providing their candidate understandings of news tellings so far, and news tellers may repeat such formulations to return to their news telling activity and assert their rights to do so (the same applies for providers and recipients of explanations, and so on). In the case of collaborative completions, speakers who have had their turn-in-progress completed by another speaker may be particularly keen on extending their turn, and repeats seem to be effective ways of doing so (see also Oloff, 2014), thus claiming primary authority over what has been said.

The study also contributes to understanding the broader matter of 'repetition' in interaction. Research in the domain of person reference formulations, for example, shows that while noun phrases (e.g., names like "Joan") are typically used in initial formulations, subsequent formulations are normally done with anaphoric forms such as 'she', which are unmarked in terms of action. The use of a repeat of the initial formulation (e.g. "Joan") instead of an anaphoric reference in the subsequent turns is marked (e.g. Fox, 1987; Raymond et al., 2021). In other words, there seem to be moments in talk-in-interaction when speakers wish to claim primary authority of what is being said or done rather than simply rely on a form that is 'parasitic' on prior talk simply by its sequential position of being next to something prior. Our analyses of doing repeating to pave the way for turn extension is another example of how speakers can claim 'agency' or authority where it might otherwise be backgrounded by a normative organisation of talk.

In short, our target phenomenon, multi-unit turns with an initial turn-constructional unit that re-says the whole of the prior speaker's turn, is a practice to claim back the rights to the content of a turn - the turn that is repeated - and tilt the entitlement to continue speaking.

\section{Acknowledgments}

We would like to thank everyone who was part of the 2017 Summer Institute for Advanced Conversation Analysis at the University of Colorado, Boulder, who importantly contributed to our thinking about repeats and turn extension. Louise Bradley, Marco Pino and Tomoyo Takagi were originally members of our group that began to explore this phenomenon. We especially appreciate the support of the instructors, Paul Drew, Barbara Fox, John Heritage, Chase Raymond, Jeffrey Robinson, and Marja-Leena Sorjonen, who encouraged us to pursue this research. Finally, thank you to the anonymous reviewers whose feedback helped us further refine the analysis and argumentation.

\section{References}


Blakemore, D., 1988. So as a constraint on relevance. In: Kempson, R.M. (Ed.), Mental Representations: the Interface between Language and Reality. Cambridge University Press, Cambridge, pp. 183-195.

Bolden, G., 2009. Beyond answering: repeat-prefaced responses in conversation. Commun. Monogr. 76 (2), $121-143$.

CLAPI, Corpus de Langue Parlée en Interaction, No date, ICAR, CNRS UMR 5191 and Université Lyon 2. Available at: clapi.ish-lyon.cnrs.fr

Clayman, S.E., Raymond, C.W., 2015. Modular pivots: a resource for extending turns at talk. Res. Lang. Soc. Interact. 48 (4), $388-405$.

Couper-Kuhlen, E., Selting, M., 2017. Interactional Linguistics: an Introduction to Language in Social Interaction. Cambridge University Press, Cambridge.

De Souza, J., 2009. Do prescrito ao realizado: as demandas interacionais das ligações para o disque saúde da mulher e sua relação com as instâncias de prescrição do trabalho de atender. MA Thesis. Universidade do Vale do Rio dos Sinos, Brazil.

Enfield, N.J., Stivers, T., Brown, P., Englert, C., Harjunpää, K., Hayashi, M., Heinemann, T., Hoymann, G., Keisanen, T., Rauniomaa, M., Raymond, C.W., Rossano, F., Yoon, K.-E., Zwitserlood, I., Levinson, S.C., 2019. Polar answers. J. Ling. 55 (2), 277-304.

Fox, B.A., 1987. Discourse Structure and Anaphora: Written and Conversational English. Cambridge University Press, Cambridge, UK.

Garfinkel, Harold, 1967. Studies in ethnomethodology. Prentice-Hall.

Goodwin, C., 1996. Transparent Vision. In: Ochs, E., Schegloff, E.A., Thompson, S.A. (Eds.), Interaction and Grammar. Cambridge University Press, Cambridge, pp. 370-404.

Goodwin, M.H., Goodwin, C., 1986. Gesture and coparticipation in the activity of searching for a word. Semiotica 62 (1/2), $51-75$.

Guimarães, E., 2007. Talking about Violence: Women Reporting Abuse in Brazil. PhD Thesis. University of York, UK.

Heritage, J., 1984. A change-of-state token and aspects of its sequential placement. In: Atkinson, J.M., Heritage, J. (Eds.), Structures of Social Action: Studies in Conversation Analysis. Cambridge University Press, Cambridge, pp. 299-345.

Heritage, J., 2012. Epistemics in action: action formation and territories of knowledge. Res. Lang. Soc. Interact. 45 (1), 1-29.

Heritage, J., Raymond, G., 2012. Navigating epistemic landscapes: acquiescence, agency and resistance in responses to polar question. In: De Ruiter, J.P. (Ed.), Questions: Formal, Functional and Interactional Perspectives. Cambridge University Press, Cambridge, pp. 179-192.

Heritage, J., Sorjonen, M.L., 1994. Constituting and maintaining activities across sequences: and-prefacing as a feature of question design. Lang. Soc. 23 (1), $1-29$.

Kristiansen, E.D., Marstrand, A.K., Derbas, J.E., 2017. Repeating a searched-for word with an agreement token in "challenged interaction”. Res. Lang. Soc. Interact. 50 (4), 388-403.

Lerner, G.H., 1996. On the semi-permeable character of grammatical units in conversation: conditional entry into the turn space of another speaker. In: Ochs, E., Schegloff, E.A., Thompson, S.A. (Eds.), Interaction and Grammar. Cambridge University Press, Cambridge, pp. $238-276$.

Lerner, G.H., 2004. Collaborative turn sequences. In: Lerner, G.H. (Ed.), Conversation Analysis: Studies from the First Generation. John Benjamins, Amsterdam/Philadelphia, pp. 225-256.

Local, J., Walker, G., 2004. Abrupt-joins as a resource for the production of multi-unit, multi-action turns. J. Pragmat. 36 (8), $1375-1403$.

Mondada, L., 2019. Conventions for multimodal transcription. https://www.lorenzamondada.net/multimodal-transcription.

Malabarba T (2010) 0 trabalho do professor de inglês em curso livre: Na tessitura das prescrições [Teaching English as a foreign language: the multifaceted nature of its institutional requirements]. MA Thesis, Universidade do Vale do Rio dos Sinos, Brazil.

Oloff, F., 2014. L'évaluation des complétions collaboratives: analyse séquentielle et multimodale de tours de parole co-construits, 19-23 July 2014. In: Neveu, F., Blumenthal, P., Hriba, L., Gerstenberg, A., Meinschaefer, J., Prévost, S. (Eds.), CMLF 2014 - 4 ème Congrès Mondial de Linguistique Française. Germany, Berlin, pp. 2125-2145 (Les Ulis: EDP Sciences).

Ostermann, A.C., De Souza, J., 2011. As demandas interacionais das ligações para o disque saúde e sua relação com o trabalho prescrito. Alfa 55 (1), $135-162$. Persson, R., 2015a. Registering and repair-initiating repeats in French talk-in-interaction. Discourse Stud. 17 (5), $583-608$.

Persson, R., 2015b. Indexing one's own previous action as inadequate: on ah-prefaced repeats as receipt tokens in French talk-in-interaction. Lang. Soc. 44 (4), 497-524.

Raymond, G., 2003. Grammar and social organization: yes/no type interrogatives and the structure of responding. Am. Socio. Rev. 68 (6), $939-967$.

Raymond, C.W., Clift, R., Heritage, J., 2021. Reference without anaphora: on agency through grammar. Linguistics: Interdiscip. J. Lang. Sci. forthc.

Sacks, H., Schegloff, E.A., 1973. Opening up closings. Semiotica 8 (4), 289-327.

Sacks, H., Schegloff, E.A., Jefferson, G., 1974. A simplest systematics for the organization of turn-taking for conversation. Language 50 (4), $696-735$.

Schegloff, E.A., 1982. Discourse as an interactional achievement: some uses of ?uh huh? and other things that come between sentences. In: Tannen, D. (Ed.), Analyzing Discourse: Text and Talk. Georgetown University Press, Washington DC, pp. 71-93.

Schegloff, E.A., 1996. Confirming allusions: toward an empirical account of action. Am. J. Sociol. 102 (1), $161-216$.

Schegloff, E.A., 2004. On dispensability. Res. Lang. Soc. Interact. 37 (2), 95-149.

Schegloff, E.A., 2007. Sequence Organization in Interaction: A Primer in Conversation Analysis. Cambridge University Press, Cambridge.

Schegloff, Emmanuel A., 2009. A practice for (re-)exiting a sequence: And/but/so + uh(m) + silence. Language in Life, And a Life in Language: Jacob Mey - a Festschrift. Brill, pp. 365-374.

Schegloff, E.A., Lerner, G.H., 2009. Beginning to respond: well-prefaced responses to Wh-questions. Res. Lang. Soc. Interact. 42 (2), $91-115$.

Selting, M., 2007. Lists as embedded structures and the prosody of list construction as an interactional resource. J. Pragmat. 39 (3), 483-526.

Stivers, T., 2005. Modified repeats: one method for asserting primary rights from second position. Res. Lang. Soc. Interact. 38 (2), $131-158$.

Stoenica, I.M., 2014. Répétition et différenciation dans les reprises structurelles intégrant des relatives. TRavaux NEuchâtelois de Linguistique 60, $209-220$.

Traverso, V., 2012. Organisation du cadre participatif, accord et répétition dans l'interaction, 4-7 July, 2012. In: Neveu, F., Muni Toke, V., Blumenthal, P., Klingler, T., Ligas, P., Prévost, S., Teston-Bonnard, S. (Eds.), CMLF 2012 - 3e Congrès Mondial de Linguistique Française. France, Lyon, pp. 663-679 (Les Ulis: EDP Sciences).

Urbano, H., Fávero, L.L., Andrade, M.L.C.V.O., Aquino, Z.G.O., 2002. Perguntas e respostas na conversacão. In: De Castilho, A.T. (Ed.), Gramática do Português Falado. Editora da Unicamp, Campinas, pp. 75-97.

Ursi, B., Etienne, C., Oloff, F., Mondada, L., Traverso, V., 2018. Diversité des répétitions et des reformulations dans les interactions orales: Défis analytiques et conception d'un outil de détection automatique. Langages 212 (4), 87-104.

Walker, G., 2010. The phonetic constitution of a turn-holding practice: rush-throughs in English talk-in-interaction. In: Barth-Weingarten, D., Reber, E., Selting, E. (Eds.), Prosody in Interaction. John Benjamins, Amsterdam/Philadelphia, pp. 51-72. 